\title{
PENGAPLIKASIAN DAN MANFAAT PROSES KEPERAWATAN DALAM TINDAKAN ASUHAN KEPERAWATAN
}

\section{Dewi Meylinta Sembiring Dewimeylinta7@gmail.com}

\section{LATAR BELAKANG}

Menjadi seorang perawat tentunya harus memiliki kualitas yang baik sehingga klien akan puas dengan mendapatkan pelayanan asuhan keperawatan dari kita. Bagaimana menjadi perawat yang baik dan berkualitas? Yaitu dengan memahami konsep proses keperawatan yang mana tujuan umum dari proses keperawatan adalah sebuah system, yang tujuannya adalah peningkatan kualitas. Maka system pada proses keperawatan akan menciptakan pelayanan asuhan keperawatan yang berkualitas dengan indicator teratasimya semua maslaah yang terkait dengan kebutuhan dasar klien.

Proses keperawatan adalah serangkaian tindakan yang sistematis yang dilakukan oleh perawat bersama klien dalam menentukan kebutuhan asuhan keperawatan denngan melakukan pengkajian,menentukan diagnosa, merencanakan tindakan, implementasi serta mengevaluasi hasil asuhan yang telah diberikan denga berfokus pada klien, berorintasi pada tujuan, serta setiap tahap saling terjadi ketergantungan dan saling berhubungan.

Asuhan keperawatan adalah rangkaian interaksi perawat dengan klien dan lingkungannya untuk mencapai tujuan pemenuhan kebutuhan dan kemandirian klien dalam merawat drinya (UU $38 / 2014)$

Proses keperawatan merupakan alat bagi perawat untuk melaksanakan asuhan keperawatan yang dilakukan pada klien memiliki arti penting yakni dapat meningkatkan kemandirian pada perawat dalam melaksanakan tugasnya karena didaam proses keerawatan terhadap metode-metode ilmiah keperawatan yang berupa langkah-langkah proses keperawatan, dapat meningjatkan kepercayaan diri perawat dalam melaksanakan tugas, dapat meningkatkan kemampuan intelektual dan teknikal dalam tindakan keperawatan, dapat meningkatkan rasa tanggung jawab. 


\section{METODE}

Metode yang digunakan adalah metode kualitatif dan metode literature review, yaitu dengan mengumpulkan data, membaca, mengkaji dan menganalisis data tersebut dari berbagai sumber seperti buku teks, e-book,jurnal,buku referensi yang berhubungan dengan tema yaitu proses keperawatan kemudian menyimpulkannya . Literature yang digunakan adalah sebanyak 11 dari berbagai sumber dengan ketentuan tahun terbit terakhir adalah tahun 2012 atau paling lama diterbitkan 8 tahun terakhir.

\section{HASIL}

Definisi proses keperawatan secara umum dapat dibedakan menjadi tiga dimensi, yaitu Tujuan ,Organisasi, dan Properti/karateristik . a. Tujuan ,proses keperawatan secara umum adalah untuk menyusun kerangka konsep berdasarkan keadaan individu (klien), keluarga, dan masyarakat agar kebutuhan mereka dapat terpenuhi dan meningkatkan kualitas asuhan keperawatan pada klien. b. Organisasi, Proses keperawatan dikelompokkan menjadi lima tahap,yaitu pengkajian, diagnosis, perencanaan, implementasi, dan evaluasi. Kelima tahap tersebutberperan sebagai organisasi yang mengelola proses keperawatan secara sistematik dalammemberikan asuhan keperawatan kepada klien. c. Properti/Karakteristik, Proses keperawatan mempunyai enam karakteristik, yaitu tujuan, Sistematis, Dinamik, Interaktif,Fleksibel, dan Teoritis

Teori yang melandasi proses keperawatan yaitu : 1.Teori Sistem, terdiri dari suatu kerangka kerjayang berhubungan dengan keseluruhan social,manusia,stuktur dan masalahmasalah organisasi serta perubahan hubungan internal dan lingkungan sekitarnya. Komponen system: input,proses dan output. Hubungan antara teori system dan proses keperawatan Input dan proses adalah suatu kumpulan data hasil pengkajian serta masalah yang ditemukan,disusun suatu rencana dan tindakan keperawatan yang tepat.dan menjelaskan hasil dari tindakan yang telah dilaksanakan 2. Teori KDM, Teori ini memandang manusia sebagai bagian integral yang 1 sama lain dalam memenuhi kebutuhan dasar:fisiologi,keamanan,kasih saying,harga diri,aktualisasi diri ( MASLOW) Peran perawat adalah memenuhi KDM dan tercapainya kepuasan dagi diri sendiri dan klien. 3.Teori Persepsi, Masalah kesehatan yang samaakanmenimbulkan masalah 
keperawatanyang berbedakarena persepsi kedua klien tersebut .Terjadinya perubahandalam pemenuhan KDM sangat dipengaruhi oleh persepsi individu.4. Teori informasi dan komunikasi, Perawat harus mengetahui komunikasi yang baik agar mudah menerapkan proses keperawatan,hasil dari penerapan proses keperawatan yang member kepuasan pada klien dan dirinya sendiri akan diinfrmasikan dengan akurat dan tepat. 5. Teori Pengambilan Keputusan dan Penyelesaian masalah, Setiap tindakan yang dilakukan dengan benar selalu melibatkan proses pengambilan keputusan dan penyelesaian masalah klien.tujuan tersebut hanya dapat tercapai apabila perawat menyusun langkah langkah pengambilan keputusan melalui tahapan proses keperawatan.Salah satu tujuan dari keperawatan adalah menyelesaikan masalah yang dihadapi klien. Melaui pendekatan proses keperawatan masalah-masalah yang dihadapi dapat diidentifikasi secara tepat dan keputusan dapat diambil secara akurat.

Penerapan Proses keperawatan mempunyai implikasi atau dampak terhadap : Profesi Keperawatan, Klien dan Perawat. Selain meningkatkan kualitas asuhan keperawatan, banyak sekali manfaat dari penerapan proses keperawatan bagi perawat, yaitu : a. Perawat akan memiliki rasa percaya diri, akan lebih percaya diri dalam memberikan asuhan keperawatan, karena semua perencanaan sudah sipersiapkan terlbih dahulu dengan baik dan tepat berdasarkan diagnosa keperawatan yang ditunjang oleh data yangtepat. b. Perawat akan memberikan peningkatan kualitas asuhan keperawatan. Dengan meningkatnya kualitas asuhan keperawatan maka semua klien mengalami kesembuhan,dan ini tentunya memberikan rasa puas tersendiri bagi anda. c. Pengembangan profesionalisme perawat. d. Proses keperawatan terdokumentasi dengan baik, akan memudahkan tenaga kesehatanlainnya untuk memberikan pelayanan kesehatan yang tepat.

\section{PEMBAHASAN}

Berdasarkan pencarian dari berbagai literature yang sesuai dengan judul dan pokok pembahasan yaitu pengaplikasian dan manfaat dari proses keperawatan dalam tindakan asuhan keperawatan, berikut adalah pembahasan dari hasil yang didapat.

Langkah-langkah dalam melakukan proses keperawatan ada 5 langkah, berikut adalah penjelasan dan contoh pengaplikasiannya dalam tindakan asuhan keperawatan. 


\section{Tahapan Pengkajian}

Tahap pengkajian merupakan pemikiran dasar dalam memberikan asuhan keperawatan sesuai dengan kebutuhan individu. Pengkajian yang lengkap, akurat, sesuai kenyataan, kebenaran data sangat penting untuk merumuskan suatu diagnosa keperawatan dan dalam memberikan asuhan keperawatan sesuai dengan respon individu. Tujuan Pengumpulan Data ialah memperoleh informasi tentang keadaan kesehatan klien, Untuk menentukan masalah keperawatan dan kesehatan klien, Untuk menilai keadaan kesehatan klien., Untuk membuat keputusan yang tepat dalam menentukan langah-langkah berikutnya.

Fokus pengkajian keperawatan ditujukan pada respon klien terhadap masalah-masalah kesehatan yang berhubungan dengan pemenuhan kebutuhan dasar manusia. Misalnya dapatkah klien melakukan aktivitas sehari-hari, sehingga fokus pengkajian klien adalah respon klien yang nyata maupun potensial terhadap masalah-masalah aktifitas harian. Karakteristik Data yang dikumpulkan adalah, lengkap,nyata dan relevan. Sumber Data bisa didapatkan dari sumber data primer (utama) yaitu klien, Sumber data sekunder yaitu Orang terdekat klien (jika klien mengalami gangguan keterbatasan dalam berkomunikasi atau kesadaran yang menurun, misalnya klien bayi atau anak-anak, atau klien dalam kondisi tidak sadar.) Sumber data lainnya seperti catatan medis dan anggota tim kesehatan lainnya (biasa terjadi pada pasien yang dirujuk), riwayat penyakit pemeriksaan fisik yang diperoleh dari terapis.

Tipe Data yaitu Data Subjektif dan data objektif. Data Subjektif adalah data yang didapatkan dari klien sebagai suatu pendapat terhadap suatu situasi dan kejadian. Misalnya tentang nyeri, perasaan lemah, ketakutan, kecemasan, frustrasi, mual, perasaan malu. Data Objektif adalah data yang dapat diobservasi dan diukur, dapat diperoleh menggunakan panca indera (lihat, dengar, cium, raba) selama pemeriksaan fisik. Misalnya frekuensi nadi, pernafasan, tekanan darah, edema, berat badan, tingkat kesadaran. Metode pengumpulan data bisa melalui wawancara, observasi,pemeriksaan fisik, studi Dokumentasi.

Berikut dipaparkan sebuah contoh kasus dan contoh singkat mengenai pengaplikasian dari pengkajian data 


\section{KASUS :}

Pada tanggal 22 Juni 2010, pukul 11.30 WIB Ny. S datang ke UGD dengan keluhan diare selama 2 hari. Klien berumur 50 th dan mengatakan sudah diare selama 2 hari. BAB encer berlendir dengan frekuensi 4-5 kali setiap harinya. Menurut hasil observasi perawat badan klien

panas, warna dan bau feses khas. Setelah ditanya kembali klien mengatakan sebelumnya makan makanan pedas.Berdasarkan pemeriksaan fisik didapatkan tanda-tanda vital :

$\begin{array}{llll}\text { Tensi } & : 110 / 70 \mathrm{mmHg} & \text { Nadi } & : 78 \mathrm{x} / \text { menit } \\ \text { RR } & : \text { 20x/menit } & \text { Suhu } & : 37,5 \mathrm{C} \\ \text { Keadaan umum } & : \text { Lemah. } & \text { Mukosa bibir } & : \text { kering }\end{array}$

PENGKAJIAN DATA KEPERAWATAN

No. Register : 2012

Ruang : anggrek 1

Tgl/ jam MRS : 22 juni 2010, jam 11.30 WIB

Tgl pengkajian : 23 juni 2010

Dignosa medis : Gastroenteritis

\section{IDENTITAS}

a. Biodata Klien

$\begin{array}{ll}\text { Nama } & : \text { Ny.S } \\ \text { Jenis kelamin } & : \text { Perempuan } \\ \text { Umur } & : 50 \text { tahun } \\ \text { Agama } & : \text { Islam } \\ \text { Suku/Bangsa } & : \text { Jawa/Indonesia } \\ \text { Pendidikan } & : \text { SLTA } \\ \text { Pekerjaan } & : \text { Ibu rumah tangga } \\ \text { Alamat } & : \text { Gadung } 1\end{array}$




\section{RIWAYAT KESEHATAN}

a. Keluhan Utama

Klien menyatakan diare 2 hari.

b. Riwayat Penyakit Sekarang

Klien menyatakan sudah diare \pm 2 hari yang lalu sejak tanggal 20 juni 2010. Klien BAB encer,dengan frekuensi 4-5x setiap harinya ( $\pm 500 \mathrm{cc}$ ), warna dan bau khas feses. Klien menyatakan sebelumnya mengkonsumsi makanan pedas. Klien juga mengatakan badannya panas.

c. Riwayat Penyakit dahulu

Klien mengatakan sebelumnya Klien tidak pernah sakit seperti ini. Klien juga tidak pernah MRS sebelumnya.

d. Riwayat Penyakit Keluarga

Klien mengatakan tidak ada anggota keluarga yang mengalami DM, Hipertensi, dan penyakit menurun lainnya.

\section{PEMERIKSAAN FISIK}
a. Keadaan Umum : Lemah
b. Kesadaran : Composmentis
: - TD : 110/70 mmHg
- $\mathrm{N}: 78 \mathrm{x} /$ menit
- RR : 20x/menit
c. TTV
- Suhu : $37,5^{\circ} \mathrm{C}$
d. Kepala
- Ekspresi Wajah : Tenang
- Rambut $\quad$ : Rambut beruban, persebaran merata, berminyak.
- Wajah : Simetris, tidak ada luka
- Mata
- Hidung
: Sklera putih, Konjungtiva merah muda, membuka mata secara spontan
- Mulut
: Tidak ada pernapasan cuping hidung, tidak ada Secret.
- Telinga
: Tidak ada sariawan, simetris, mukosa kering
: Simetris, tidak ada serumen, fungsi pendengaran baik 
e. Abdomen

- Inspeksi $\quad$ : Bentuk perut datar

- Auskultasi $\quad$ : Bising usus $14 \mathrm{x} /$ menit

- Perkusi : : Suara hipertimpani

- Palpasi : : Tidak ada pembesaran hepar

f. Ekstermitas

- Atas : Jari lengkap, terpasang infus RA : D5 pada tangan kanan, tonus otot 5 I 5

- Bawah : Jari lengkap, tonus otot 5 I5

IV. DATA PENUNJANG

- HB : : $11,56 \quad$ Leukosit $: 6100$

- Trombosit : $154.000 \quad$ - PCU : 36

- Widal : TO : - TH : -

V. TERAPI

- Infus RA : D5 30 TMP

- Injeksi Cefotaxime 3 x 1

- Sanmol 3 x 1

- Plantasit syrup $3 \times 1$

- Luminal 2x1 / 2

\section{DATA SENJANG}

DS : - klien mengatakan diare 2 hari

- klien mengatakan BAB klien encer dengan frekuensi 4-5 x / hari

- klien mengatakan feses berbau daN berwarna khas feses

- klien mengatakan sebelumnya mengkonsumsi makanan pedas

- klien mengatakan badannya panas 
DO : - Keluhan utama Lemah

- Suhu : $37,5^{\circ} \mathrm{C} \quad$ - TD : $110 / 70 \mathrm{mmHg}$

- Nadi : 78 x/menit $\quad$ - RR : 20 x/menit

- Konsistensi feses cair - Mukosa bibir kering

- Suara perut hipertimpani

ANALISA DATA

Nama $\quad$ : Ny.S

Dx. Medis : Gastroenteritis

\begin{tabular}{|c|c|c|c|}
\hline $\mathrm{NO}$ & DATA & PENYEBAB & MASALAH \\
\hline 1. & $\begin{array}{l}\text { Klien mengatakan diare } 2 \text { hari } \\
\text { Klien mengatakan saat BAB feses } \\
\text { klien encer dan berlendir. } \\
\text { Klien mengatakan BAB 4-5X } \\
\text { dalam sehari. } \\
\text { Klien mengatakan mengonsumsi } \\
\text { makanan pedas sebelumnya. } \\
\text { Keluhan utama lemah } \\
\text { Konsistensi fases cair dan } \\
\text { berlendir } \\
\text { Mukosa bibir kering } \\
\text { Suara perut hipertimpani } \\
\text { Tugor kulit menurun } \\
\text { Klien mengatakan badan panas } \\
\text { Do: - Keluhan utama lemah } \\
\mathrm{S} \quad: 37,5^{\circ} \mathrm{C} \\
\mathrm{N} \quad: 78 \mathrm{X} / \text { menit }\end{array}$ & 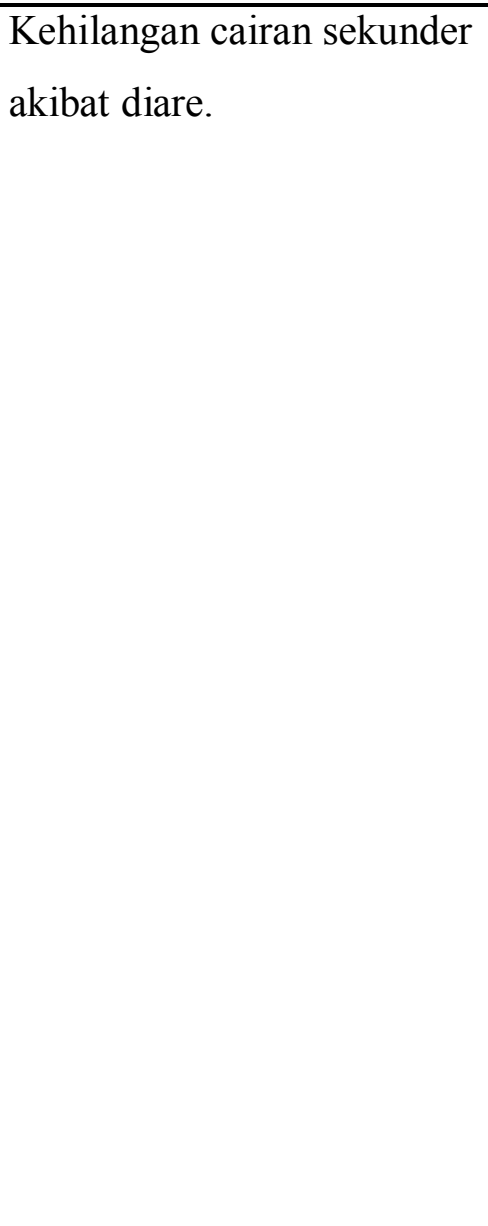 & $\begin{array}{l}\text { Ketidak seimbangan cairan } \\
\text { dan elektrolit. }\end{array}$ \\
\hline 2. & $\begin{array}{l}\mathrm{TD}: 110 / 70 \mathrm{mmHg} \\
\mathrm{RR}: 20 \mathrm{X} / \text { menit }\end{array}$ & Proses infeksi penyakit & Peningkatan suhu tubuh \\
\hline
\end{tabular}




\section{Tahapan Diagnosa}

Menurut North American Nursing Diagnosis Association (NANDA) (1990, dalam Carpenito, 1997) diagnosa keperawatan adalah keputusan klinis mengenai seseorang, keluarga atau masyarakat sebagai akibat dari masalah-masalah kesehatan/ proses kehidupan yang aktual atau risiko. Tujuan tahapan diagnosa adalah untuk mengidentifikasi kebutuhan perawatan kesehatan, untuk merumuskan diagnose keperawatan. Diagnosa keperawatan memberikan dasardasar pemilihan intervensi untuk mencapai hasil yang menjadi tanggung gugat perawat. Adapun persyaratan dari diagnosa keperawatan adalah perumusan harus jelas dan singkat dari respons klien terhadap situasi atau keadaan yang dihadapi, spesifik dan akurat, memberikan arahan pada asuhan keperawatan, dapat dilaksanakan oleh perawat dan mencerminkan keadaan kesehatan klien.

Berikut adalah contoh singkat mengenai pengaplikasian tahapan diagnosa dari kasus yang sebelumnya sudah dipaparkan pada bagian tahapan pengkajian

\section{DIAGNOSA KEPERAWATAN}

Nama : Ny.S

Dx. Medis : Gastrointeritis

\begin{tabular}{|l|l|}
\hline No & DIAGNOSA MEDIS \\
\hline 1. & $\begin{array}{l}\text { Ketidakseimbangan cairan dan elektrolit berhubungan dengan kehilangan cairan } \\
\text { sekunder. }\end{array}$ \\
2. & Hipertermi brerhubungan dengan proses infeksi penyakit. \\
\hline
\end{tabular}




\section{Tahapan Perencanaan}

Merupakan pedoman tertulis untuk perawatan klien. Tujuannya adalah ntuk mengidentifikasi tujuan klien, menentukan prioritas asuhan, merancang strategi keperawatan untuk mencapai tujuan perawatan. Dalam perencanaan keperawatan, perawat menetapkannya berdasarkan hasil pengumpulan data dan rumusan diagnosa keperawatan yang merupakan petunjuk dalam membuat tujuan dan asuhan keperawatan untuk mencegah, menurunkan, atau mengeliminasi masalah kesehatan klien.

Rencana perawatan terorganisasi sehingga setiap perawat dapat dengan cepat mengidentifikasi tindakan perawatan yang diberikan. Rencana asuhan keperawatan yang di rumuskan dengan tepat memfasilitasi konyinuitas asuhan perawatan dari satu perawat ke perawat lainnya. Sebagai hasil, semua perawat mempunyai kesempatan untuk memberikan asuhan yang berkualitas tinggi dan konsisten. Rencana asuhan keperawatan tertulis mengatur pertukaran informasi oleh perawat dalam laporan pertukaran dinas. Rencana perawatan tertulis juga mencakup kebutuhan klien jangka panjang(potter,1997)

Berikut adalah contoh singkat mengenai pengaplikasian tahapan Perencanaan dari kasus yang sebelumnya sudah dipaparkan pada bagian tahapan pengkajian

\section{PERENCANANAAN ASUHAN KEPERAWATAN}

Nama $\quad$ Ny.S

Dx.Medis : Gastroenteritis

\begin{tabular}{|c|c|c|c|c|}
\hline No & DIAGNOSA & TUJUAN & INTERVENSI & RASIONAL \\
\hline 1. & $\begin{array}{l}\text { Ketidakseimbangan } \\
\text { cairan dan elektrolit } \\
\text { berhubungan dengan } \\
\text { kehilangan cairan } \\
\text { sekunder. }\end{array}$ & $\begin{array}{l}\text { Setelah dilakukan } \\
\text { tindakan } \\
\text { keperawatan } \\
\text { dalam waktu 1X24 } \\
\text { jam diharapkan : } \\
\text { TTV dalam batas } \\
\text { normal }\end{array}$ & $\begin{array}{l}\text { 2. Pantau input dan } \\
\text { output. } \\
\text { 3. Bina hubungan saling }\end{array}$ & $\begin{array}{l}\text { 1.Penurunan volume } \\
\text { cairan dan elektrolit } \\
\text { menyebabkan dehidrasi } \\
\text { jaringan. } \\
\text { 2.Dehidrasi dapat } \\
\text { meningkatkan laju filtasi } \\
\text { glomerulus. }\end{array}$ \\
\hline
\end{tabular}




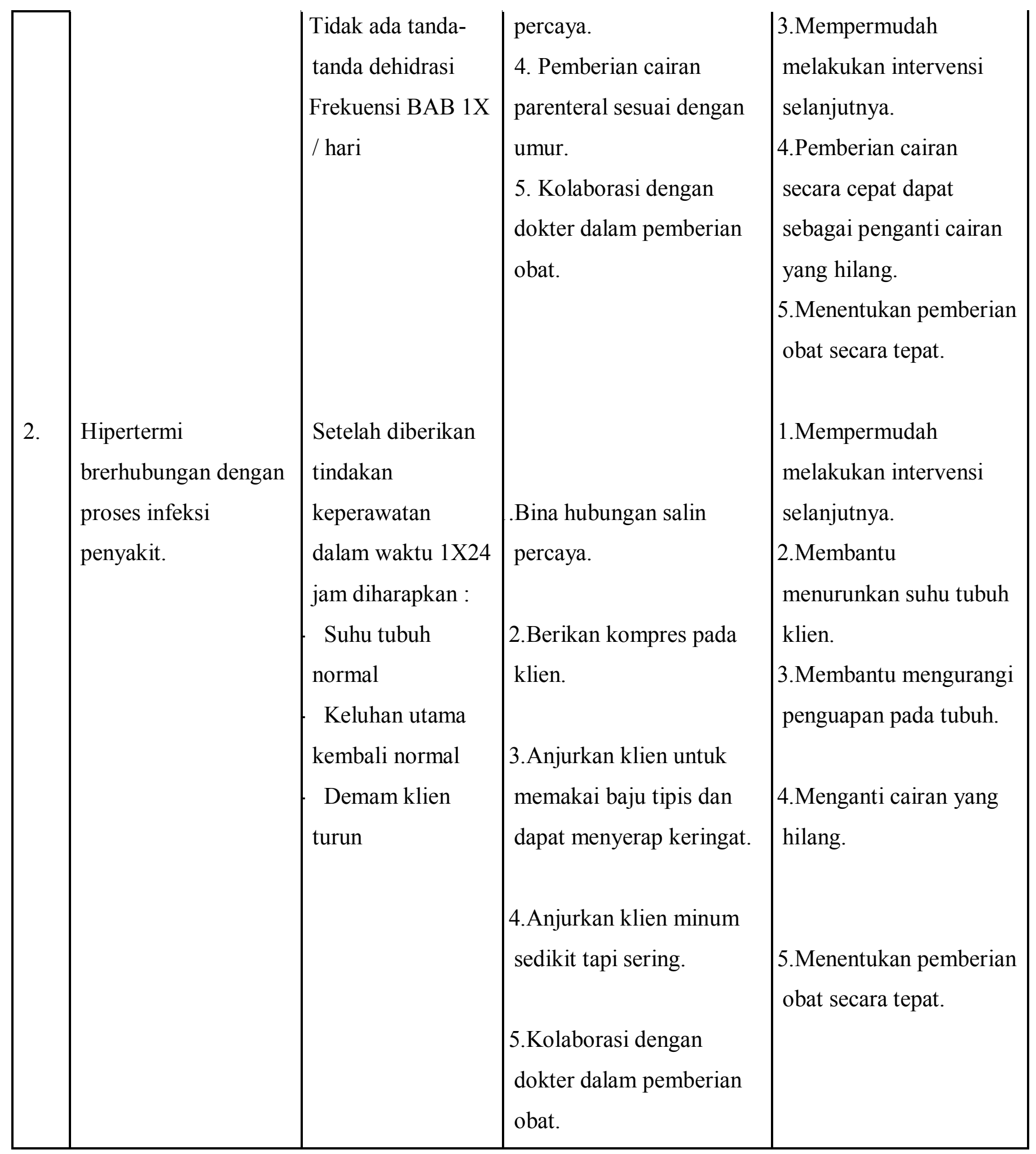




\section{Tahapan Implementasi}

Merupakan inisiatif dari rencana tindakan untuk mencapai tujuan yang spesifik. Tahap pelaksanaan dimulai setelah rencana tindakan disusun dan ditujukan pada nursing orders untuk membantu klien mencapai tujuan yang diharapkan. Oleh karena itu rencana tindakan yang spesifik dilaksanakan untuk memodifikasi faktor-faktor yang mempengaruhi masalah kesehatan klien. Adapun tahap-tahap dalam tindakan keperawatan adalah sebagai berikut :

Tahap 1 : Persiapan.

Tahap awal tindakan keperawatan ini menuntut perawat untuk mengevaluasi yang diindentifikasi pada tahap perencanaan.

Tahap 2 : Intervensi.

Focus tahap pelaksanaan tindakan perawatan adalah kegiatan dan pelaksanaan tindakan dari perencanaan untuk memenuhi kebutuhan fisik dan emosional. Pendekatan tindakan keperawatan meliputi tindakan : independen,dependen, dan interdependen.

Tahap 3 : Dokumentasi.

Pelaksanaan tindakan keperawatan harus diikuti oleh pencatatan yang lengkap dan akurat terhadap suatu kejadian dalam proses keperawatan.

Berikut adalah contoh singkat mengenai pengaplikasian tahapan Implementasi dari kasus yang sebelumnya sudah dipaparkan pada bagian tahapan pengkajian

\section{IMPLEMENTASI}

\begin{tabular}{|l|l|l|l|}
\hline $\begin{array}{l}\text { No } \\
\mathrm{dx}\end{array}$ & Tgl/jam & Implementasi & Tgl/jam \\
\hline 1. & $\begin{array}{l}22 / 06 / 1 \\
0\end{array}$ & $\begin{array}{l}\text { 1. Memantau TTV } \\
\text { 2. Memantau intake dan output dengan memperhatikan tetesan } \\
09.00\end{array}$ & $\begin{array}{l}\text { infus dan BAB, BAK klien } \\
\text { 3. Membina hubungan saling percaya dengan klien } \\
\end{array}$ \\
& $\begin{array}{l}\text { 4. Memberikan cairan parentera dengan memasang infus pada } \\
\text { klien. }\end{array}$ & \\
& 5. Mengkolaborasikan dengan dokter. & \\
\end{tabular}




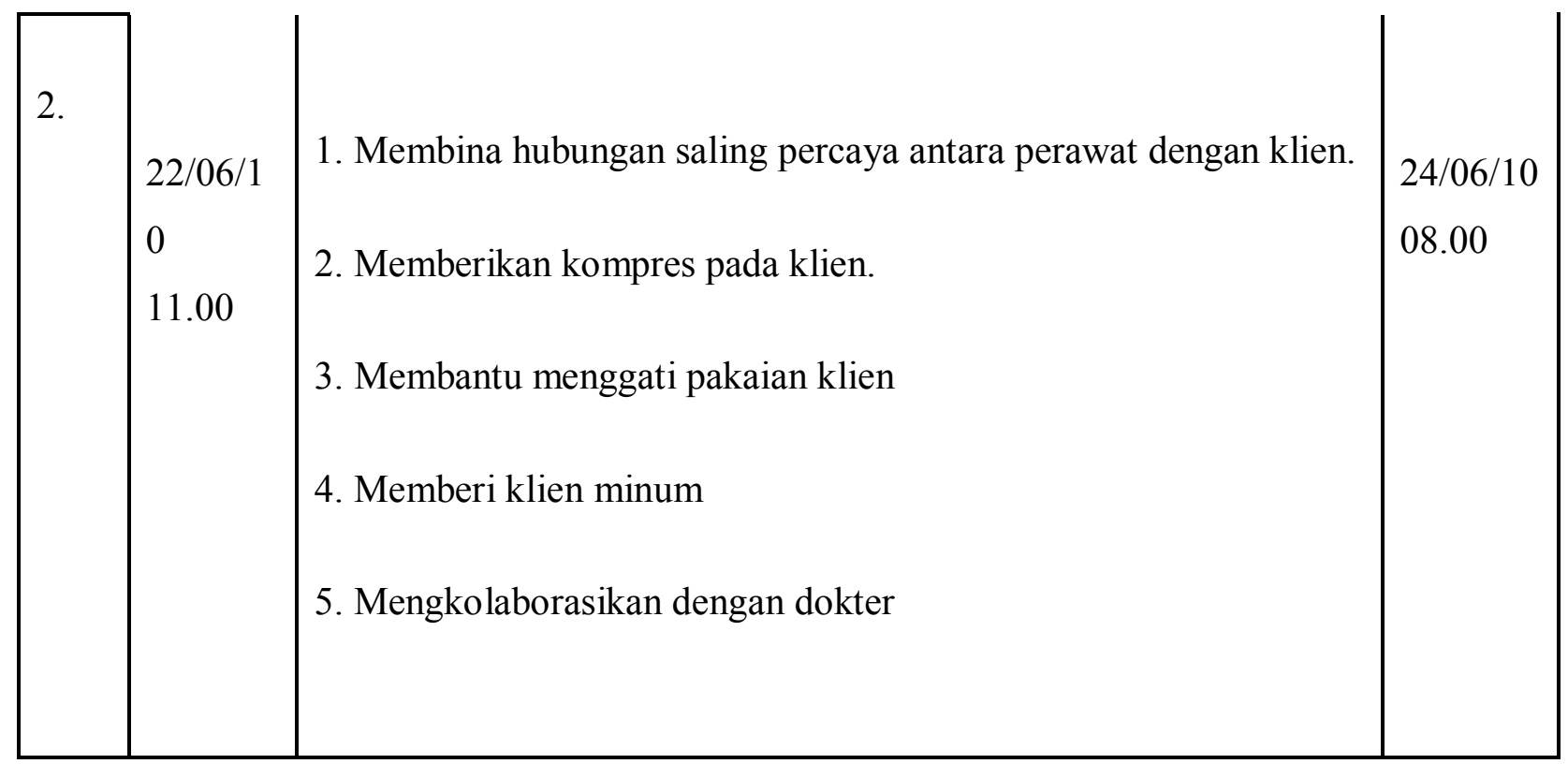

5. Tahap Evaluasi

Perencanaan evaluasi memuat kriteria keberhasilan proses dan keberhasilan tindakan keperawatan. Keberhasilan proses dapat dilihat dengan jalan membandingkan antara proses dengan pedoman/rencana proses tersebut. Sedangkan keberhasilan tindakan dapat dilihat dengan membandingkan antara tingkat kemandirian pasien dalam kehidupan sehari-hari dan tingkat kemajuan kesehatan pasien dengan tujuan yang telah di rumuskan sebelumnya.

Tahapan dalam evaluasi yaitu membandingkan respons klien dengan kriteria, menganalisis alasan untuk hasil konklusi, memodifikasi rencana asuhan.

Berikut adalah contoh singkat mengenai pengaplikasian tahapan Evaluasi dari kasus yang sebelumnya sudah dipaparkan pada bagian tahapan pengkajian

\section{EVALUASI}

\begin{tabular}{|l|l|l|l|l|l|}
\hline $\begin{array}{l}\text { No } \\
\mathrm{dx}\end{array}$ & Tgl/jam & Implementasi & Tgl/jam & Evaluasi & ttd \\
\hline 1. & $22 / 06 / 10$ & 1. Memantau TTV & $\begin{array}{l}23 / 06 / 10 \\
08.00\end{array}$ & $\begin{array}{l}\text { Klien mengatakan diare dan } \\
\text { panas } \\
\text { Keluhan utama hilang, diare }\end{array}$ & \\
\hline
\end{tabular}




\begin{tabular}{|c|c|c|c|c|}
\hline 2. & $\begin{array}{l}22 / 06 / 10 \\
11.00\end{array}$ & $\begin{array}{l}\text { tetesan infus dan BAB, BAK } \\
\text { klien } \\
\text { Membina hubungan saling } \\
\text { percaya dengan klien } \\
\text { Memberikan cairan parentera } \\
\text { dengan memasang infus } \\
\text { pada klien. } \\
\text { Mengkolaborasikan dengan } \\
\text { dokter. } \\
\text { 1. Membina hubungan saling } \\
\text { percaya antara perawat } \\
\text { dengan klien. } \\
\text { 2. Memberikan kompres } \\
\text { pada klien. } \\
\text { 3. Membantu menggati } \\
\text { pakaian klien } \\
\text { dengan dokter }\end{array}$ & $\begin{array}{l}24 / 06 / 10 \\
08.00\end{array}$ & $\begin{array}{l}\text { Klien mengatakan diare } \\
\text { sudah jarang dan klien } \\
\text { sudah tidak panas } \\
\text { keluhan utama hilang, diare } \\
\text { cair tapi berampas, } \\
\text { frekuensi 1-2 x/hari, panas } \\
\text { hilang, } \mathrm{T}=120 / 80 \mathrm{mmHg}, \\
\mathrm{S}=36,5 \mathrm{C} \\
\mathrm{A} \text { : Masalah teratasi } \\
\text { Intervensi dihentikan }\end{array}$ \\
\hline
\end{tabular}

Jika seluruh proses keperawatan sudah diterapkan pada tindakan asuhan keperawatan maka tidak hanya menguntungkan bagi perawat namun klien juga merasakan keuntungannya. Secara singkat, proses keperawatan membuat tindakan asuhan keperawatan mengalami peningkatan kualitas dalam asuhan keperawatan dan dengan begitu klien menjadi puas. Berikut adalah penjelasan secara lebih rinci . 


\section{a. Profesi}

Secara profesional, Proses keperawatan menyajikan suatu lingkup praktik keperawatan. Melaluilima langkah, Keperawatan secara terus-menerus mendefinisikan perannya kepada klien dan profesi kesehatan lainnya. Hal ini menunjukkan bahwa keperawatan tidak hanya melaksanakan rencanaseperti yang telah diresepkan dokter (Iyeret al 1996).Praktik keperawatan mencakup standar praktik keperawatan. Standar tersebut diadopsi danditerbitkan oleh American Nursing Association (ANA) pada tahun 1973. Perawat Mempunyaitanggung jawab dalam melaksanakan tugasnya sesuai dengan standar praktik keperawatan tanpamelihat dimana dia bekerja dan apa spesialisasinya. Di Indonesia pelaksanakan standar praktikkeperawatan juga telah diatur dalam peraturan pemerintah melalui Undang-Undang Kesehatan diIndonesia (Depkes, 1992) dan akan diberlakukan PERMENKES No. 647/2000 tentang PraktikKeperawatan Profesional di Indonesia.

b. Klien

Penggunaan Proses keperawatan sangat bermanfaat bagi klien, keluarga, dan masyarakat karenamendorong mereka untuk berpartisipasi secara aktif dengan melibatkan mereka ke dalam limatahapannya. Klien menyediakan sumber untuk pengkajian, validasi diagnosis keperawatan, danmenyediakan umpan balik untuk evaluasi. Perencanaan keperawatan yang tersusun dengan baikakan memungkinkan perawat untuk memberikan asuhan keperawatan secara kontinu, aman, danmenciptakan lingkungan yang terapeutik. Keadaan tersebut akan membantu mempercepatkesembuhan klien dan memungkinkan klien untuk beradaptasi dengan limgkungan yang ada.

c. Perawat

Proses Keperawatan akan meningkatkan kepuasan dalam bekerja dan meningkatkan perkembanganprofesional. Peningkatan hubungan antara perawat dengan klien dapat dilakukan melalui penerapanproses keperawatan. Proses keperawatan memungkinkan suatu pengembangan kreativitas dalammenjelaskan masalah klien. Hal ini mencegah kejenuhan perawat dalam melakukan pekerjaan yangbersifat rutinitas serta mencegah perawat untuk melakukan pendekatan yang berorientasi terhadaptugas (task-oriented approach). 


\section{PENUTUP}

Kesimpulan

Proses keperawatan adalah serangkaian tindakan yang sistematis yang dilakukan oleh perawat bersama klien dalam menentukan kebutuhan asuhan keperawatan denngan melakukan berbagai tahapan yaitu pengkajian,menentukan diagnosa ,merencanakan tindakan, implementasi serta mengevaluasi hasil asuhan yang telah diberikan denga berfokus pada klien, berorintasi pada tujuan, serta setiap tahap saling terjadi ketergantungan dan saling berhubungan.

Penerapan/pengaplikasian proses keperawatan dalam asuhan keperawatan dapat dikatakan baik apabila perawat sudah melaksanakan tahap-tahap dalam proses keperawatan terhadap pasien yaitu tahap pengkajian,menentukan diagnosa ,merencanakan tindakan serta mengevaluasi hasil asuhan yang telah diberikan dengan berfokus pada klien

Jika seluruh proses keperawatan sudah diterapkan pada tindakan asuhan keperawatan maka tidak hanya menguntungkan bagi perawat namun klien juga merasakan keuntungannya.Secara umum, proses keperawatan membuat tindakan asuhan keperawatan mengalami peningkatan kualitas dalam asuhan keperawatan dan dengan begitu klien menjadi puas.

\section{DAFTAR PUSTAKA}

Astar Fatmawati, Hasmin Tamsag, Ikhasan Kadir. (2017). Pengaruh pelayanan asuhan keperawatan terhadap kepuasan pasien di puskesmas Takalala kabupaten Soppeng. Jurnal of managemenet, 1(2),33-57.

Budiono. (2016). Konsep Dasar Keperawatan. Jakarta: Kementrian Kesehatan Republik Indonesia.

Budiono \& sumirah.(2015). Konsep dasar keperawatan. Jakarta: Bumi Medika.

Hermawan Deden.(2012). Proses keperawatan : penerapan konsep \&kerangka kerja. Jakarta : Gosyen Publishing. 
Kasim Mohammmad, Mohammad Abdurouf. (2016). Peningkatan Kualitas Pelayanan Dan Pendokumentasian Asuhan Keperawatan Dengan Metode Tim. Jurnal keperawatan Universitas Islam Sultan Agung, 1(1),62-72.

Rohmah, Nikmatur and Walid, Saiful.(2016). Proses Keperawatan : Teori \& Aplikasi. Jogjakarta: AR-RUZZ MEDIA

Simamora, R. H. (2019). Development of Guidelines for Applying appropriate Patient Identification to Achieve Patient Safety Goal INC2019 12th International Nursing Conference. 2019.10455 - 455 (1 pages) UCI(KEPA) : I410-ECN-0101-2019-512-001224337

Simamora. R. H. (2008) The correlation of ward chief's giving direction and command and the performance of on-duty nurses at Jember dr. Subandi general hospital inpatient wards. jurnal Administrasi dan Kebijakan Kesehatan, (https://fkm.unair.ac.id/jurnal-administr)

Wartonah \& Tartowo. (2014). Kebutuhan dasar dan proses keperawatan. Jakarta : Salemba Medika.

Wirdah Husnul, Muhammad yusuf. (2016). Penerapan asuhan keperawatan oleh perawat pelaksana dirumah sakit banda aceh. Jurnal ilmiah mahasiswa fakultas keperawatan, 1(1),1-6.

Wulansari Putri, Heni Apriyani. (2016). Diagnosis Keperawatan Pada Pasien Dengan Gangguan Pencernaan. Jurnal keperawatan,12(1),40-45.

Yeni Fitra. (2014). Pengaruh Pelatihan Proses Keperwatan terhadap Dokumentasi Asuhan Keperawatan di Puskesmas Kabupaten Agam Provinsi Sumatera Barat. Jurnal Keperawatan universitas Andalas ,10(1), 21-27. 